\title{
The Pleiotropic Role and Perplexing Mechanism of Action of Vitamin D in Attention Deficit Hyperactivity Disorder
}

\author{
Shaily A Amin ${ }^{1,3 *}$, Abul BMMK Islam² and Anuradha Reddy ${ }^{1}$ \\ ${ }^{1}$ Dept of Psychiatry, Virginia Tech Carilion School of Medicine, Virginia \\ ${ }^{2}$ Riverside Circle, Roanoke, Virginia \\ ${ }^{3}$ Dept of Genetic Engineering, University of Dhaka, Bangladesh \\ *Corresponding author: Shaily A Amin, Dept of Psychiatry, Virginia Tech Carilion School of Medicine, Virginia, USA
}

\begin{tabular}{|c|c|}
\hline ARTICLE INFO & ABSTRACT \\
\hline Received: 茂 January 10, 2020 & Citation: Shaily A Amin, Abul BMMK Islam, Anuradha Reddy. The Pleiotropic Role and \\
\hline Published: 櫘 January 17, 2020 & $\begin{array}{l}\text { Perplexing Mechanism of Action of Vitamin D in Attention Deficit Hyperactivity Disor- } \\
\text { der. Biomed J Sci \& Tech Res 24(4)-2020. BJSTR. MS.ID.004083. }\end{array}$ \\
\hline
\end{tabular}

\section{Introduction}

Vitamin D (Vit.D) has tantalizing effects as a neurosteroidal micronutrient in the brain [1]. The essential role of Vit.D, $1 \alpha$-hydroxylase, and their nuclear receptors, Vit.D-Receptors (VDR) are underappreciated as they regulate proliferation and differentiation of neurons, synaptic plasticity, neurotrophic and neuroprotective actions in the human brain [1]. Deficiencies in Vit.D in animal models show abnormal growth of brain and neurons, reduction in NGF, dopamine, and several neurotrophic factors [2]. Furthermore, during adulthood, Vit.D deficiency exacerbated underlying brain disorders and/or worsen recovery from brain stressors [2]. There is mounting epidemiological studies that indicate that Vit.D deficiency is associated with a broad range of neuropsychiatric disorders and neurodegenerative diseases [1-3]. Thus effects of Vit.D deficiencies [ $\leq 20 \mathrm{ng} / \mathrm{L}]$ in psychiatric diseases, especially in Attention-Deficit/Hyperactivity Disorder (ADHD) remains ambiguous [3].

\section{Vitamin D; A Risk Factor in ADHD}

Higher levels of circulating maternal Vit.D [in 1,650 motherchild pairs] during gestation significantly decreased risk/symptoms associated with ADHD-affected adolescents [4]. Nine different human meta-analysis [representing $\sim 10,200$ subjects] showed that Vit.D deficiency was significantly prevalent [but not in all ADHD subjects] in each study in children diagnosed with ADHD vs. casecontrols [5]. These clinical observations implicate the essential role of Vit.D in early brain development and initial childhood. ADHDaffected adolescents in the health disparity, Appalachian region of Virginia showed Vit.D deficiencies in $>80 \%$ of the individuals (Amin $S$ et al., *Presented at American Academy of Child and Adolescent Psychiatry's 66th Annual Meeting in Chicago on October 14-19, 2019). VDRs were also significantly low in adolescents with ADHD.

\section{Supplementation of Vitamin D May Influence Some} Symptoms of ADHD

Surprisingly, some of the Vit.D-deficiency-induced symptoms in ADHD may be reversible. The effect of supplementing 2000U to $50,000 \mathrm{U}$ of Vit.D showed significant improvement [using WCST, CPRS and WIS scales] in cognitive tasks at the conceptual level, a decline in hyperactivity, inattention, and impulsivity [6]. Furthermore, Vit.D [2000IU] supplemented for 8 weeks as adjunctive therapy to methylphenidate $[1 \mathrm{mg} / \mathrm{kg}]$ showed a significant increase in the levels: (a) of serum Vit.D [ $\geq 30 \mathrm{ng} / \mathrm{L}$ ] (b) improvement in the evening symptoms of ADHD based on the WPREMB scale but showed no difference in CPRS and ADHD-RS scales [7]. The differential levels of Vit.D on [some symptoms or risk of] ADHD are discreet but statistically significant. 


\section{The Complex Mechanism of Action of Vitamin D in ADHD}

The neuroprotective action of Vit.D in the brain is complex involving multiple molecular mechanisms [1-3]. Vitamin D + VDR can interact with $\sim 900$ different proteins and regulate $\sim 600$ genes which include multifunctional inflammatory mediators [e.g., IL-1 $\beta$, $\mathrm{TNF} \alpha$ ], reactive oxygen species, and synthesis of serotonin, opioids, oxytocin, and dopamine [1-3]. The genomics analysis of Vit.D gene via the Integrative Psychiatric Research (iPSYCH2012) with 18,726 subjects with ADHD may shed further light on the genetics, the nutritional and environmental aetiology of ADHD [8].

\section{Conclusion}

The effects of Vit.D in ADHD are subtle and significant. These unobtrusive differences invite controversies due to lack of statistical analysis, sample sizes, study design, acceptable clinical outcome scales and/or considering genetic and epigenetic factors in investigations. Further investigations [with large stratified cohorts of race/ethnicities, skin color, outcome scales, exposure to sunlight, dietary habits, and socioeconomic status] are required to elucidate the risk-benefit ratio on the effects of Vit.D in ADHD. Although the exact mechanism[s] of action of Vit.D in the brain concerning ADHD remains evasive, several theories suggest that Vit.D may augment dopamine signaling that regulates the tonic excitatory drive and controls the frequency of brain rhythms [1]. In conclusion, the pleiotropic role of Vit.D is intertwined in the onset, pathogenesis, progression, and clinical management of ADHD. We believe the supplementation and therapeutic use of Vit.D warrants further fine-tuning among different genotypes and caution [on long term effects] since potential users are high-risk individuals like pregnant women, nursing infants, and ADHD-affected individuals.
Disclosures and Acknowledgment. Dr. Amin, Islam and Reddy report no competing interest. The author thanks Drs A. Kablinger, T. Badratnakaran and M. Singal at Virginia Tech and /or Carillion School of Medicine for their guidance and input during the preparation of this manuscript. *The unpublished data reported here will be presented as an abstract and poster at the American Academy of Child and Adolescent Psychiatry's 66th Annual Meeting in Chicago on October 14-19, 2019.

\section{References}

1. Groves N, McGrath J, Burne T (2014) Vitamin D as a neurosteroid affecting the developing and adult brain Annu Rev Nutr 34: 117-141.

2. Féron F, Burne TH, Brown J, Smith E, McGrath JJ, et al. (2005) Developmental Vitamin D3 deficiency alters the adult rat brain. Brain Res Bull 65(2): 141-148.

3. Saedisomeolia A, Samadi M, Gholami F (2018) Vitamin D’s Molecular Action Mechanism in Attention-Deficit Hyperactivity Disorder: A Review of Evidence. CNS \& Neurological Disorder-Drug Targets 17: 280-290

4. Morales E, Julvez J, Torrent M, Ballester F, Rodríguez-Bernal CL, et al (2015) Vitamin D in Pregnancy and Attention Deficit Hyperactivity Disorder-like Symptoms in Childhood. Epidemiology 26(4): 458-465.

5. Khoshbakht Y, Bidaki R, Salehi-Abargouei A (2018) Vitamin D Status and Attention Deficit Hyperactivity Disorder: A Systematic Review and MetaAnalysis of Observational Studies. Adv Nutr 9(1): 9-20.

6. Elshorbagy HH, Barseem NF, Abdelghani WE, Suliman HAI, Al-Shokary $\mathrm{AH}$, et al. (2018) Impact of Vitamin D Supplementation on AttentionDeficit Hyperactivity Disorder in Children. Ann Pharmacother 2(7) :623663.

7. Mohammadpour N, Jazayeri S, Tehrani-Doost M, Djalali M, Hosseini M, et al. (2018) Effect of vitamin D supplementation as adjunctive therapy to methylphenidate on ADHD symptoms: A randomized, double-blind, placebo-controlled trial. Nutr Neurosci 21(3): 202-209.

8. Pedersen CB, Bybjerg-Grauholm J, Pedersen MG, Grove J, Agerbo E, et al. (2018) The iPSYCH2012 case-cohort sample: New directions for unravelling genetic and environmental architectures of severe mental disorders. Mol Psychiatry 23(1): 6-14.
ISSN: 2574-1241

DOI: $10.26717 /$ BJSTR.2020.24.004083

Shaily A Amin. Biomed J Sci \& Tech Res

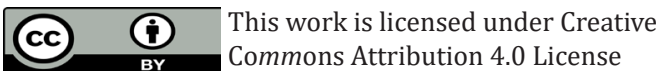

Submission Link: https://biomedres.us/submit-manuscript.php

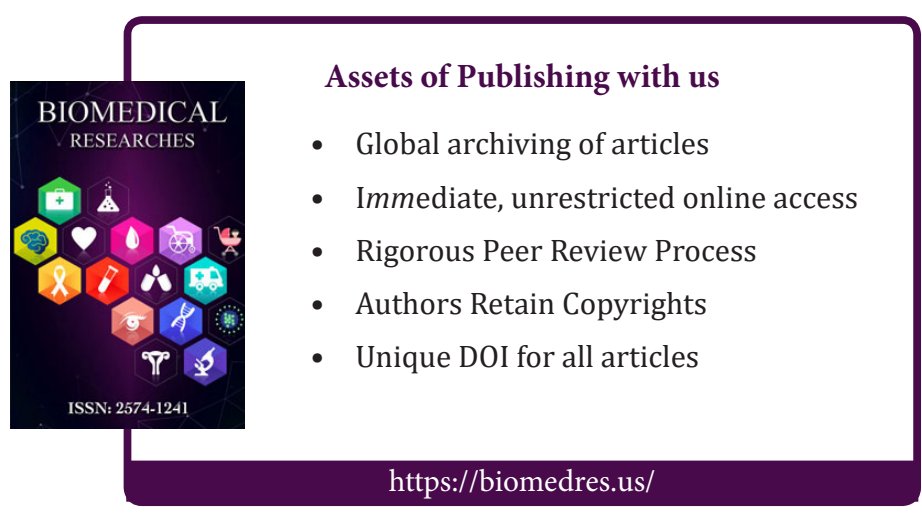

